Check for updates

Cite this: RSC Adv., 2019, 9, 7411

Received 30th November 2018 Accepted 20th February 2019

DOI: $10.1039 / \mathrm{c} 8 \mathrm{ra09838g}$

rsc.li/rsc-advances

\section{Synthesis of a novel flame retardant based on DOPO derivatives and its application in waterborne polyurethane}

\author{
Hui Wang, Shuang Wang, Xiaosheng Du, (D) Haibo Wang, (D) Xu Cheng \\ and Zongliang Du*
}

An intumescent flame retardant (DOPO-DAM) containing phosphorus and nitrogen was synthesized via a two-step process and then, it was incorporated into waterborne polyurethane to serve as a reactive flame retardant for preparing flame-retarded WPU (FR-WPU). The chemical structures of DOPO-DAM and FR-WPU were confirmed by ${ }^{1} \mathrm{H} N M R,{ }^{31} \mathrm{P} N M R$, and FTIR studies. The thermal stability, flame retardancy and mechanical properties of FR-WPU were investigated by TGA, TGA-FIR, Py-GC-MS, limiting oxygen index (LOI) test, SEM-EDS analysis, cone calorimeter test and a universal testing machine. The results showed that the conjugation of DOPO-DAM into WPU induced a slight decline in the thermal stability of FR-WPU. However, the incorporation of DOPO-DAM into WPU significantly enhanced the flame retardancy by reducing the heat release rate (HRR), total heat release (THR), smoke production rate (SPR) and total smoke production (TSP). In addition, the morphology, elemental composition and content of the residual char of the flame-retarded WPU indicated the important function of DOPO-DAM in the condensed phase. Thus, DOPO-DAM exhibited gas-phase and condensed-phase flame retardant effects on the WPU films.

\section{Introduction}

Waterborne polyurethane (WPU) is regarded as one of the most versatile materials with advantages such as high chemical resistance, excellent flexibility and good adhesion. Thus, it has been extensively employed in industry and day-to-day activities such as adhesive manufacturing, leather finishing, textile laminating, automobiles and wood coatings. ${ }^{\mathbf{1 - 5}}$ However, the polyurethane materials are highly flammable with a high heat release rate and smoke production (even toxic gases) during combustion, which restricts their further applications. ${ }^{6}$ To overcome this drawback of WPU, flame retardants have been used to improve the flame retardancy of the WPU matrix.

Generally, there are two main approaches to introduce flame retardants into WPU, including additive-type or reactive-type flame retardants. The former has negative effects on the mechanical properties and compatibilities of WPU. ${ }^{7,8}$ Meanwhile, the flame retardancy can deteriorate during burning due to the migration of FR because of the lack of strong covalent attachment of PU. In contrast, the reactive flame retardants have become an integral part of the polymer materials and lead to permanent combustion resistance. ${ }^{9}$ Therefore, it has become a trend of preparing reactive flame retardants for WPU.

Textile Institute, College of Light Industry, Textile and Food Engineering, Sichuan University, Chengdu,610065, China.E-mail:dzl407@163.com
Traditionally, halogen flame retardants are effective in improving the flame retardancy of polymers, but they release toxic gases such as dibenzo- $p$-dioxin and hydrogen halide during combustion. ${ }^{10}$ Hence, it is necessary to promote the development of halogen-free flame retardants. In recent years, halogen-free flame retardants containing phosphorus, nitrogen, silicon, boron and other flame-retarded elements have been widely developed and applied in polyurethane fabrication. ${ }^{11-17}$ Among them, phosphorus-containing flame retardants, especially 9,10-dihydro-9-oxa-10phosphaphenanthrene-10-oxide (DOPO) and its derivatives, have attracted much attention. Compared with other linear lowmolecular-weight phosphonates, phosphorous compounds, DOPO and its derivatives display high thermal stability, excellent flame retardancy and low toxicity due to the presence of cyclic phosphate groups with a diphenyl structure. ${ }^{18}$ DOPO and its derivatives play flame-retardant roles in the condensed phase and enhance the flame-retardant property of polymers. ${ }^{19-22} \mathrm{Wu}$ et al. ${ }^{23}$ synthesized phosphorous-containing polyols to improve the combustion resistance of rigid PU foams; the modified polyols did not affect the physical and thermomechanical properties of PU foams and showed better fireretardant effects than the commercial flame retardant Fyrol 6. König et al. ${ }^{\mathbf{2 4 2 5}}$ synthesized new phosphorus flame-retardant methyl-DOPO in a flexible polyurethane foam and then contributed to the gas-phase activity of flame inhibition. Gaan et $a .^{26}$ and Rao et $a .^{27}$ synthesized DOPO-based 
phosphonamidate additives and incorporated them in the polyurethane manufacturing process. The above-mentioned studies indicate that DOPO phosphonamidates exhibit better flame-retardant efficiency than the commercial flame retardants. However, the DOPO as physical blending agent is usually used to modify the flame retardation of polyurethane, but the little work about DOPO as reactive additive modified WPU has been studied. Moreover, flame retardants have an effective synergistic effect when combining phosphorus with nitrogen elements ${ }^{28}$ to prepare a DOPO-based intumescent flame retardant (IFR). It can further reduce the additive amount of flame retardants and retain the high flame-retardant efficiency simultaneously. ${ }^{29,30}$

In this work, an intumescent flame retardant (DOPO-DAM) containing phosphorus and nitrogen was synthesized successfully by the combination of formaldehyde, diethanolamine and DOPO through a two-step process. DOPO-DAM as a reactive flame retardant was then incorporated into waterborne polyurethane to prepare FR-WPU. The mechanical properties, thermal properties and flame retardancy of WPU were investigated by TGA, LOI, SEM, cone calorimeter tests and a universal testing machine. The flame-retardant mechanism of DOPODAM was also studied by a series of tests.

\section{Experiments}

\section{Materials}

9,10-Dihydro-9-oxa-10-phosphaphenanthrene 10-oxide (DOPO) of reagent grade was provided by Huaxia Chemical Industry Co. (Chengdu, China). Formaldehyde, acetone, diethanolamine, $\mathrm{N}, \mathrm{N}$-dimethylformamide (DMF), ethanol, 1,4-dioxane, triethylamine (TEA), and 1,4-butanediol (BDO) were supplied by Kelong Reagent Co. (Chengdu, China). Poly(propylene glycol) (PPG 2000, $\mathrm{Mn}=2000 \mathrm{~g} \mathrm{~mol}^{-1}$ ), dimethylolpropionic acid (DMPA), isophorone diisocyanate (IPDI), and dibutyltin dilaurate (DBTDL, catalyst) were purchased from American Geo. Co. (PA, Unites States). BDO was dehydrated with 4-A molecular sieves for $24 \mathrm{~h}$. PPG 2000 and DMPA were dehydrated under vacuum at $120{ }^{\circ} \mathrm{C}$ for $3 \mathrm{~h}$. Distilled water was self-made in the laboratory.

\section{Instrumentations}

The ${ }^{1} \mathrm{H}$ NMR and ${ }^{31} \mathrm{P}$ NMR analyses were performed using a BRUKER AC-400 Advance spectrometer at $400 \mathrm{MHz}$. The sample was dissolved in dimethyl sulfoxide- $d_{6}$ (DMSO- $d_{6}$ ) at a concentration of $\sim 1 \mathrm{w} / \mathrm{v} \%$. Fourier transform infrared (FTIR) spectra were recorded using a Nicolet 560 FTIR spectrometer (Nicolet, Waltham, MA) at ambient temperature in the region from 4000 to $600 \mathrm{~cm}^{-1}$. The average particle sizes of FR-WPU dispersions were measured using a Zetasizer Nano Model laser particle size analyzer (Malvern Instruments, UK). The dispersion samples were tested at an ambient temperature after dilution to $0.5 \mathrm{wt} \%$. The limiting oxygen index test was carried out using an HC-2C oxygen index meter (Nanjing Jiangning Analytical Instrument Co., Ltd, China) according to the ASTM-D 2863-2009 standard to measure the minimum oxygen concentration. The dimensions of the specimens were $127 \times 10 \times 3$ $\mathrm{mm}^{3}$. The cone calorimeter testing was conducted using an FTT cone calorimeter (Grinstead, UK) according to the ISO 5660-1 standard. The dimensions of the specimens were $100 \times 100 \times 3$ $\mathrm{mm}^{3}$. Thermogravimetric analysis was conducted using a TGA Q500 thermal analyzer (TA Instruments, New Castle, DE). FRWPU films (approximately $5 \mathrm{mg}$ ) were tested over the range from ambient temperature to $600{ }^{\circ} \mathrm{C}$ at a scanning rate of $20{ }^{\circ} \mathrm{C} \min ^{-1}$ under nitrogen atmosphere. TG-IR spectroscopy was conducted using a Nicolet 10 TG-IR spectrometer. FR-WPU films (approximately $10 \mathrm{mg}$ ) were tested over the range from ambient temperature to $600{ }^{\circ} \mathrm{C}$ at a scanning rate of $10{ }^{\circ} \mathrm{C} \mathrm{min}{ }^{-1}$ under nitrogen atmosphere. Py-GC/MS was performed using a Pyroprobe (CDS5000) instrument. The pyrolyzer was coupled with a GC/MS operator (Agilent 6890/5073). The polymer was pyrolyzed at $280{ }^{\circ} \mathrm{C}$ under helium atmosphere. Then, the volatilized pyrolysis products were separated and analyzed using a mass spectrometer. The SEM and the energy dispersive spectroscopy (EDS) analyzer employed a Quanta 250 scanning electron microscope (FEI, Hillsboro) to analyze the morphologies and the elemental distributions of char residues. The char residues were obtained after the cone calorimeter test and made electrically conductive by sputtering with gold.

\section{Synthesis of 9,10-dihydro-9-oxa-10-[N,N-bis-(2- hydroxyethylamino-methyl)]-10-phosphaphenanthrene-10- oxide (DOPO-DAM)}

DOPO-DAM was prepared according to a previously reported procedure, ${ }^{31}$ as illustrated in Scheme 1. Formaldehyde (27.0 g, $37 \%$ in water, $0.33 \mathrm{~mol})$, diethanolamine $(35.0 \mathrm{~g}, 0.33 \mathrm{~mol})$ and DBTDL (0.05 wt\%) were added into a three-necked glass reactor equipped with a mechanical stirrer, a thermometer, and a condenser tube. The mixture was stirred at $35^{\circ} \mathrm{C}$ for $4 \mathrm{~h}$. Then, the mixture was heated to $80{ }^{\circ} \mathrm{C}$ and evaporated to remove the generated water. DOPO $(72.0 \mathrm{~g}, 0.33 \mathrm{~mol})$ were dissolved in $50 \mathrm{~mL}$ 1,4-dioxane and charged into the above reactor; after that, the mixture was stirred at $70{ }^{\circ} \mathrm{C}$ for another $4 \mathrm{~h}$. Then, evaporation of 1,4-dioxane. The reaction mixture was washed with ethanol three times. A white solid was obtained after drying in a vacuum oven at $100{ }^{\circ} \mathrm{C}$ for $4 \mathrm{~h}$. The yield was $92.0 \%$.

\section{Synthesis of flame-retardant waterborne polyurethane dispersions}

Flame-retardant waterborne polyurethanes (FR-WPU) were synthesized according to a procedure reported by Wang et al. ${ }^{32}$ The reaction was carried out in a three-necked glass reactor equipped with a mechanical stirrer and a condenser tube. First, $19.5 \mathrm{~g}$ IPDI, $30.0 \mathrm{~g}$ PPG 2000, $2.8 \mathrm{~g}$ DMPA, and $0.05 \mathrm{wt} \%$ DBTDL were added into the reactor. Then, the mixture in the reactor was kept at $80{ }^{\circ} \mathrm{C}$ for $3 \mathrm{~h}$. Afterwards, different ratios of BDO and DOPO-DAM were added into the reactor until the theoretical -NCO value was reached. The change in the NCO value during the reaction was determined by the standard dibutylamine back-titration method (ASTM D 2572-87). At the end of the reaction, the temperature was cooled down to $50{ }^{\circ} \mathrm{C}$ and then, acetone was added to adjust the viscosity of the WPU pre- 


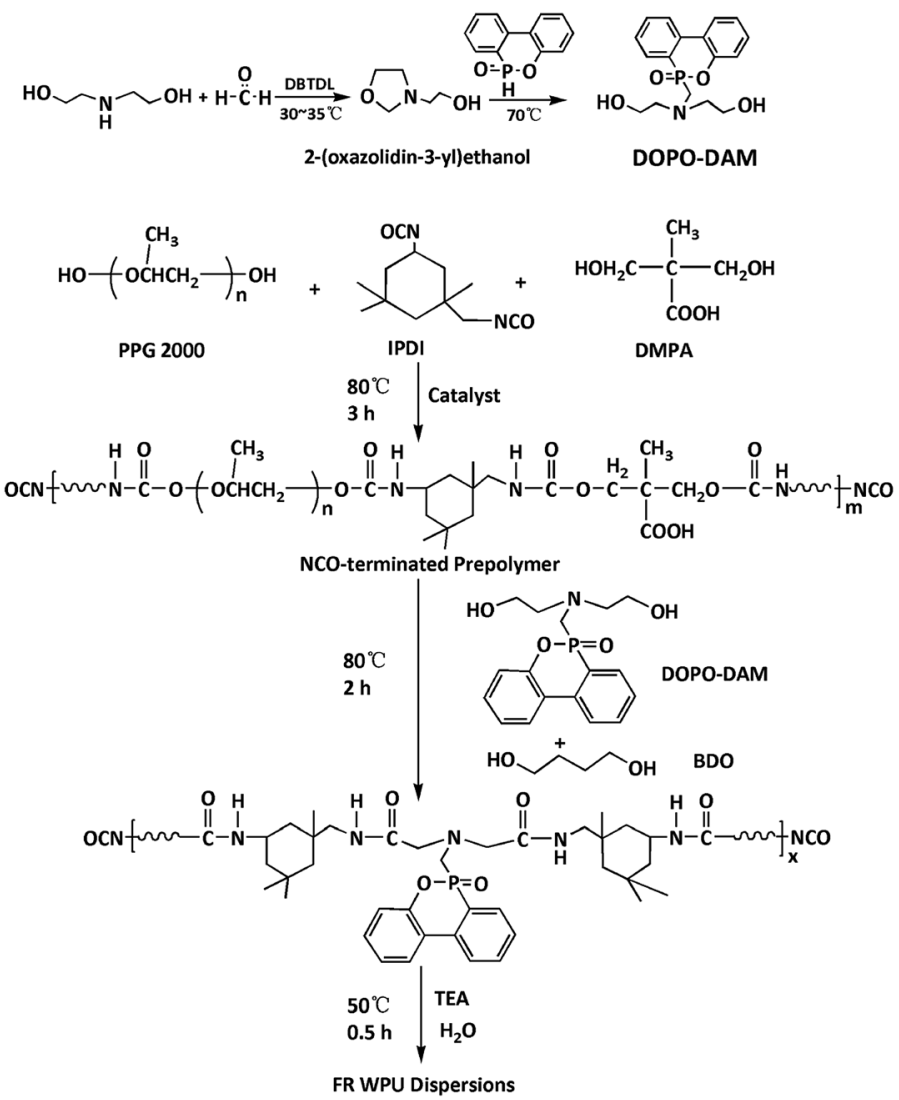

Scheme 1 The synthetic route of DOPO-DAM and FR-WPU dispersions.

polymer. The WPU pre-polymer was neutralized below $50{ }^{\circ} \mathrm{C}$ by $2.1 \mathrm{~g}$ TEA. Finally, distilled water was added to the mixture under vigorous dispersion (1200 rpm) to prepare a series of FRWPU materials. After evaporation of acetone, FR-WPU with a solid content of $30 \mathrm{wt} \%$ was obtained. The chemical composition of FR-WPU and the particle size of FR-WPU dispersions (Table 1). The synthetic route of FR-WPU dispersions is provided in Scheme 1. FR-WPU in this study was referred to as WPU- $x$, where $x$ indicates the DOPO-DAM concentration.

\section{Preparation of WPU films}

The waterborne polyurethane dispersions were placed in Teflon templates for $7 \mathrm{~d}$ at room temperature. After evaporation of water, WPU films were dried in a vacuum oven at $60^{\circ} \mathrm{C}$ for $24 \mathrm{~h}$ to obtain transparent polyurethane films.

\section{Results and discussion}

\section{Characteristics of DOPO-DAM}

The intermediate and DOPO-DAM samples were characterized by ${ }^{1} \mathrm{H}$ and ${ }^{31} \mathrm{P}$ NMR, as shown in Fig. 1. In Fig. 1(a), the intermediate exhibits some strong peaks. The multiplet peaks appearing at $4.15,3.60$, and $2.52 \mathrm{ppm}$ are attributed to the methylene protons in penta-heterocycles. The chemical shift at $3.60 \mathrm{ppm}$ is assigned to the methylene protons adjacent to tertiary amine nitrogen. The peak at $2.87 \mathrm{ppm}$ is attributed to the methylene protons linked with $-\mathrm{OH}^{33}$ The ${ }^{1} \mathrm{H}$ NMR spectra of DOPO-DAM shown in Fig. 1(b) demonstrate the structure: the peak at $2.50 \mathrm{ppm}$ corresponds to the proton of DMSO; the peak at $3.17 \mathrm{ppm}$ is attributed to the chemical shift of $-\mathrm{CH}_{2}-$ linked with $\mathrm{N}\left(-\mathrm{CH}_{2}-, 4 \mathrm{H}\right)$; the peak at $3.24 \mathrm{ppm}$ is attributed to the chemical shift of $-\mathrm{CH}_{2}-$ linked with $-\mathrm{OH}\left(-\mathrm{CH}_{2}-, 4 \mathrm{H}\right)$; the peak

Table 1 The chemical composition of FR-WPU and the particle size of FR-WPU dispersions

\begin{tabular}{|c|c|c|c|c|c|c|}
\hline Sample & DOPO-DAM/g & $\mathrm{BDO} / \mathrm{g}$ & Particle sizes/nm & PDI & $\mathrm{P}^{a} / \mathrm{wt} \%$ & $\mathrm{P}^{b} / \mathrm{wt} /$ oo \\
\hline WPU-0 & 0 & 3.26 & 68.74 & 0.042 & 0 & 0 \\
\hline WPU-3 & 1.75 & 2.79 & 70.31 & 0.051 & 2.86 & 2.79 \\
\hline WPU-6 & 3.50 & 2.32 & 70.82 & 0.052 & 5.60 & 5.41 \\
\hline WPU-9 & 5.25 & 1.84 & 78.00 & 0.124 & 8.22 & 7.91 \\
\hline
\end{tabular}

${ }^{a} \mathrm{P}$ content $=[$ mass $(\mathrm{P})] /[$ mass $(\mathrm{PPG} 2000+\mathrm{IPDI}+\mathrm{DMPA}+\mathrm{DOPO}-\mathrm{DAM}+\mathrm{BDO})] \times 1000 .{ }^{b} \mathrm{P}$ content was determined by EDS. 

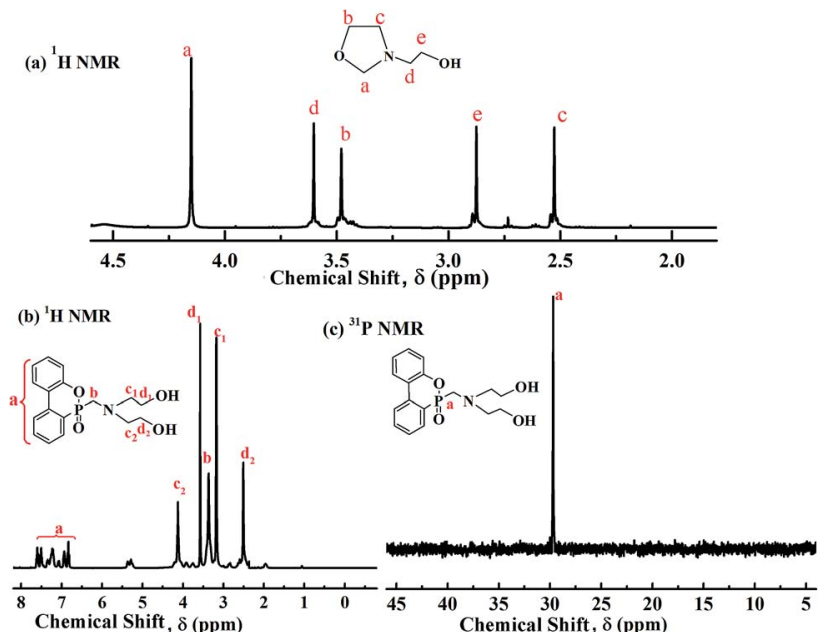

Fig. $1{ }^{1} \mathrm{H}$ (a) spectra of intermediate in DMSO- $d_{6} ;{ }^{1} \mathrm{H}$ (b) and ${ }^{31} \mathrm{P}$ (c) NMR spectra of DOPO-DAM in DMSO- $d_{6}$.

at $3.72 \mathrm{ppm}$ is assigned to the chemical shift of $-\mathrm{CH}_{2}-$ linked with $\mathrm{P}$ group; the peak at $4.12 \mathrm{ppm}$ is assigned to the proton of the $-\mathrm{OH}$ groups; the chemical shifts at 6.8-7.6 ppm are due to $\mathrm{Ar}-\mathrm{H}$ of the biphenyl group of DOPO. As shown in Fig. 1(c), only one specific absorption peak at $29.72 \mathrm{ppm}$ is observed in the ${ }^{31} \mathrm{P}$ NMR spectrum of DOPO-DAM. It was deduced that the target product of a phosphorus-containing diol was successfully synthesized.

The synthesized FR-WPU films were characterized by FTIR. As shown in Fig. 2, the FTIR spectra display strong absorptions at $3329 \mathrm{~cm}^{-1}$ corresponding to the $\mathrm{N}-\mathrm{H}$ stretching vibration of urethane bond; the peak at $1539 \mathrm{~cm}^{-1}$ corresponds to $\mathrm{N}-\mathrm{H}$ deformation, and the peak at $1710 \mathrm{~cm}^{-1}$ is assigned to the $-\mathrm{C}=$ $\mathrm{O}$ groups in urethane. The asymmetrical and symmetrical stretching absorption bands for $-\mathrm{CH}_{3}$ and $-\mathrm{CH}_{2}-$ groups were confirmed by the peaks at $2979 \mathrm{~cm}^{-1}$ and $2864 \mathrm{~cm}^{-1}$. For WPU6 , the new peaks at $1220 \mathrm{~cm}^{-1}$ and $1028-927 \mathrm{~cm}^{-1}$ were assigned to the $\mathrm{P}=\mathrm{O}$ stretching and the stretching vibrations of $\mathrm{P}-\mathrm{O}-\mathrm{Ar}$, respectively. The peak at $3064 \mathrm{~cm}^{-1}$ was assigned to $\mathrm{Ar}-\mathrm{H}$. In addition, there was no significant infrared absorption peak at $3421 \mathrm{~cm}^{-1}$, which showed that -OH of polyol and DOPO-DAM completely reacted. The above analysis confirmed the successful synthesis of FR-WPU.

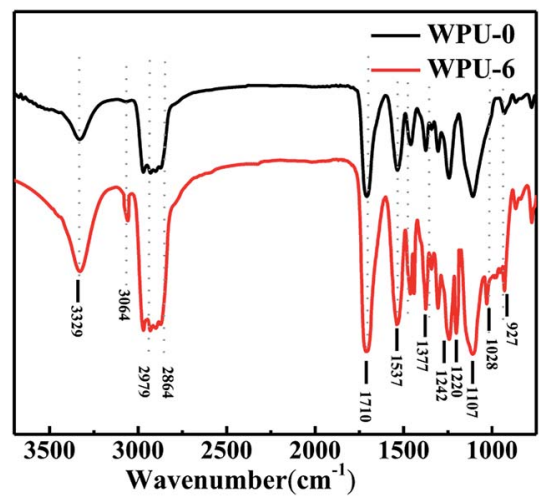

Fig. 2 FTIR spectra of WPU-0 and WPU-6.

\section{Dispersion properties}

Fig. 3 displays the influence of DOPO-DAM ratios on the particle sizes and distributions of FR-WPU dispersions and the data are listed in Table 1. It was found that the particle size distributions of WPU-0 dispersions were unimodal distribution and the average particle size of WPU-0 was about $68.74 \mathrm{~nm}$. Moreover, the average particle sizes showed an increasing trend as the DOPO-DAM ratio increased. When there was less content of DOPO-DAM, the chemical structures of DOPO-DAM exhibited negligible effect on the average particle size of FR-WPU dispersions. However, the average particle sizes increased obviously as the amount of DOPO-DAM increased due to the phosphaphenanthrene structure of DOPO-DAM. With increase in the concentration of DOPO-DAM, the diphenyl structure led to larger steric hindrance, limited the movement of the molecular chain, and consequently increased the particle size.

\section{Mechanical properties}

Fig. 4 shows the stress-strain curves of WPU films; the results are summarized in Table 2. As DOPO-DAM increased, the tensile strength and Young's modulus of WPU-3 increased first and then decreased, while the elongation at break increased gradually. The incorporation of DOPO-DAM with an appropriate content $(3 \%)$ first led to the reinforcement of tensile strength and Young's modulus on FR-WPU. Then, the tensile strength of WPU films decreased with the increasing amount of DOPODAM, while the broken elongation increased. The results were caused by the steric hindrance derived from bulky and rigid DOPO units in DOPO-DAM. This was unfavourable for regular arrangement and closely packed arrangement, resulting in unstable cohesion and hydrogen bonding interactions. It disrupted the crystallization of hard segment and restricted the inter-reaction of polyurethane chains. ${ }^{17}$

\section{Thermal behavior}

TGA and DTG curves of FR-WPU films with various contents of DOPO-DAM under nitrogen atmosphere are shown in Fig. 5. The related thermal decomposition data of the temperature at $5 \%$ weight loss $\left(T_{\mathrm{d} 5 \%}\right)$, the temperature at maximum decomposition rate $\left(T_{\max }\right)$ and the residual yield at $600{ }^{\circ} \mathrm{C}$ obtained

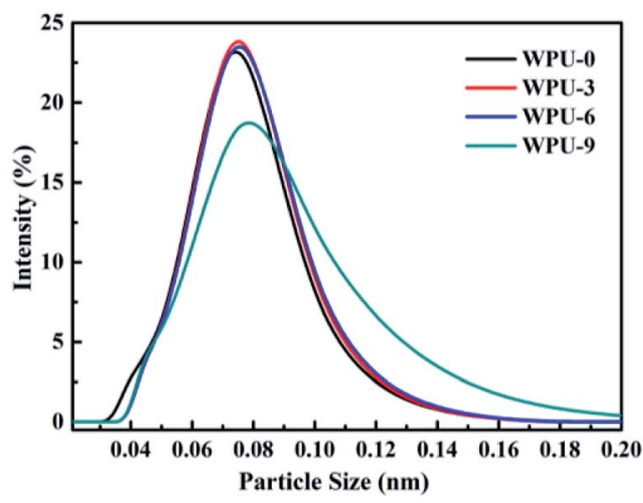

Fig. 3 Particle sizes and distributions of WPU dispersions. 


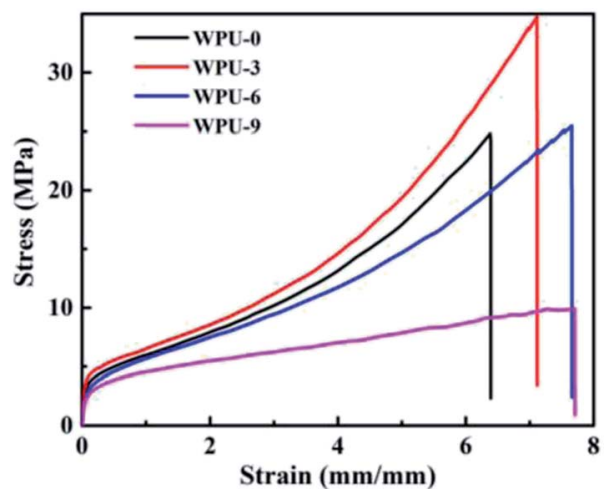

Fig. 4 Stress-strain curves for WPU films.

Table 2 Mechanical properties of WPU films

\begin{tabular}{llll}
\hline Sample & $\begin{array}{l}\text { Elongation at } \\
\text { break (\%) }\end{array}$ & Tensile strength/MPa & $\begin{array}{l}\text { Young's } \\
\text { modulus/MPa }\end{array}$ \\
\hline WPU-0 & 674 & 27.32 & 5.9 \\
WPU-3 & 743 & 34.73 & 7.6 \\
WPU-6 & 790 & 26.72 & 4.5 \\
WPU-9 & 792 & 9.92 & 1.9 \\
\hline
\end{tabular}
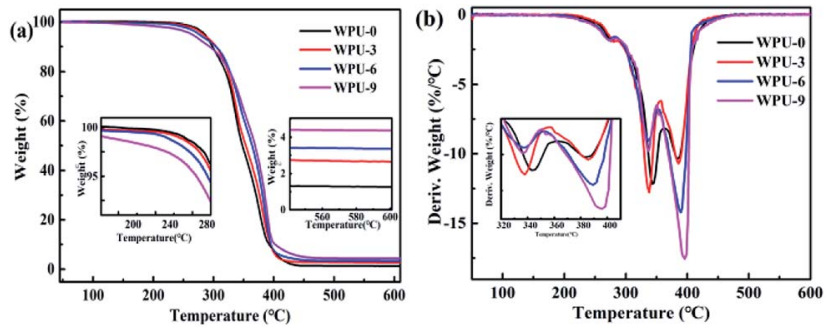

Fig. 5 TGA (a) and DTG (b) curves of FR-WPU films in $\mathrm{N}_{2}$

from the curves are given in Table 3. It exhibits the main thermal degradation process of WPU-0 mainly via two main stages with the $T_{\max }$ values at $341.1{ }^{\circ} \mathrm{C}$ and $387.8^{\circ} \mathrm{C}$, and the char yield can reach $1.21 \%$ at $600{ }^{\circ} \mathrm{C}$. The first thermal decomposition occurred between $252.4{ }^{\circ} \mathrm{C}$ and $366.2{ }^{\circ} \mathrm{C}$, which was attributed to the cleavages of the urethane bonds in the hard segment to form isocyanates, aldehydes, ketones, olefins, carbon dioxide, and water. ${ }^{20,34,35}$ The second stage occurred in the range from 366.2 to $450.4{ }^{\circ} \mathrm{C}$, which was attributed to the further decomposition of the remaining polyol chains in the soft segment. ${ }^{36}$

Table 3 TGA and DTG results for FR-WPU films

\begin{tabular}{lllll}
\hline Sample & $T_{\mathrm{d} 5 \%} /{ }^{\circ} \mathrm{C}$ & $T_{\max 1} /{ }^{\circ} \mathrm{C}$ & $T_{\max 2} /{ }^{\circ} \mathrm{C}$ & Residues $/ \mathrm{wt} \%$ \\
\hline WPU-0 & 280.1 & 343.0 & 383.2 & 1.21 \\
WPU-3 & 276.6 & 338.9 & 385.6 & 2.69 \\
WPU-6 & 271.4 & 336.5 & 390.5 & 3.40 \\
WPU-9 & 266.6 & 335.4 & 394.1 & 4.38
\end{tabular}

Compared with the result for WPU-0, a similar degradation trend was observed for the modified FR-WPU with different phosphorus contents. As presented in Table 3, there is a significant decline of the $T_{5 \%}$ value and $T_{\max 1}$ with the increase in DOPO-DAM contents in FR-WPU. The variation in $T_{\max 1}$ values was related to the thermal stability of DOPO-DAM in this temperature range. Moreover, when the amount of DOPM-DAM reached $9 \%$ in FR-WPU, $T_{\max 2}$ increased. Furthermore, the amounts of char residues at $600{ }^{\circ} \mathrm{C}$ reached $2.69 \%$, $3.40 \%$ and $4.38 \%$. This can be because the bond dissociation energy of P-C bonds $\left(264 \mathrm{~kJ} \mathrm{~mol}^{-1}\right)$ in DOPO-DAM moiety was lower than that of the $\mathrm{C}-\mathrm{C}$ bonds $\left(331 \mathrm{~kJ} \mathrm{~mol}^{-1}\right) \cdot{ }^{37}$ Thus, the breakage of the $\mathrm{P}-\mathrm{C}$ bond in DOPO-DAM produced phosphoric acid, polyphosphoric acid and its derivatives at a relatively lower temperature, which could accelerate the decomposition of flame-retardant DOPO-DAM as a strong catalyst. Moreover, the resultants decomposed earlier in the range of $180-250^{\circ} \mathrm{C}$. Then, the weight loss at the first stage could again be a result of the degradation of DOPO-DAM and urethane bonds. Additionally, in the first stage, the mass loss in the first step (approximately $33 \%$ ) fitted well with the IPDI concentration of $32.5 \%$ of the sample. The remaining decomposition product could be retained in WPU, exhibiting subsequently condensed or gas phase activity, which formed an intumescent char layer during thermal degradation and insulated the underlying polyurethane matrix from heat and flame. These results indicated that the introduction of DOPO-DAM into the polyurethane matrix can significantly improve the flame retardancy. Consequently, FRWPU films exhibit higher thermal stability at a higher temperature range and leave more char at $600{ }^{\circ} \mathrm{C}$.

In order to further study the thermal degradation behavior of WPU films, the gaseous pyrolysis products of WPU-0 and WPU-6 were investigated by TG-IR analysis. The three-dimensional TGIR spectra of the volatilized products of WPU-0 and WPU-6 obtained during the thermal decomposition process from 50 to $600{ }^{\circ} \mathrm{C}$ are presented in Fig. 6 . The FTIR spectra of the volatile products obtained at different temperatures are presented in Fig. 7. In Fig. 6, there was a difference between WPU-0 and WPU-9 during the thermal degradation process. As shown in Fig. 7(a), gases containing $\mathrm{CO}_{2},-\mathrm{NCO}$ groups and $\mathrm{HCN}(2290-$ $2372 \mathrm{~cm}^{-1}$ ) are released at $230{ }^{\circ} \mathrm{C}$ due to the cleavage of the urethane bonds (-NHCOO-) in the hard segment. Then, the gas containing - $\mathrm{OH}\left(3650-3800 \mathrm{~cm}^{-1}\right.$, such as water), hydrocarbons (2850-3000 $\left.\mathrm{cm}^{-1}\right), \mathrm{CO}_{2},-\mathrm{NCO}$ groups, $\mathrm{HCN}\left(2290-2372 \mathrm{~cm}^{-1}\right)$,
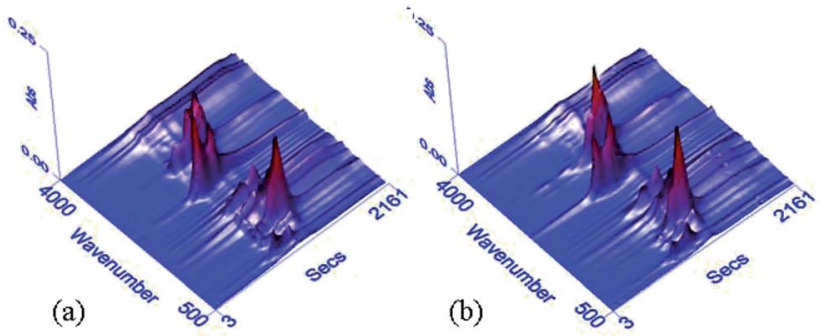

Fig. 6 The 3D TG-IR spectra of gas phase in the thermal decomposition of WPU-O (a) and WPU-6 (b). 


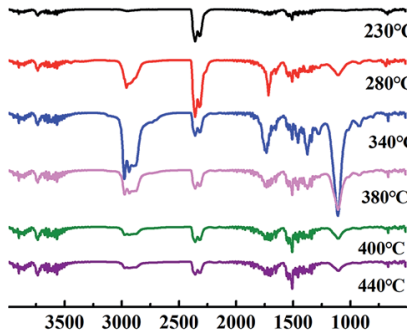

(a)

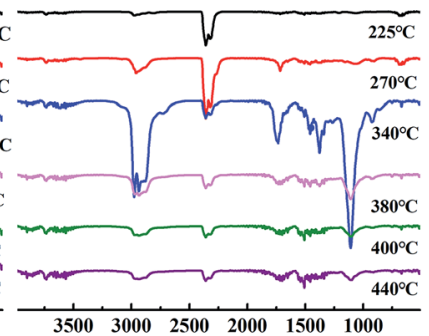

(b) Wavenumber $\left(\mathrm{cm}^{-1}\right)$

Fig. 7 RT-FTIR spectra of WPU-O (a) and WPU-6 (b) at different pyrolysis temperatures.

CO $\left(1718 \mathrm{~cm}^{-1}\right)$ and ethers (C-O-C bond, $\left.1112 \mathrm{~cm}^{-1}\right)^{38,39}$ was released when the temperature was increased to $280{ }^{\circ} \mathrm{C}$. With the temperature was increased further, the relative intensities of the typical peaks increased first and then decreased, as described previously, except for the peaks around 3650$3800 \mathrm{~cm}^{-1}$ and $1353-1544 \mathrm{~cm}^{-1}$. At $340{ }^{\circ} \mathrm{C}$, the nonflammable gas $\mathrm{NH}_{3}\left(928 \mathrm{~cm}^{-1}\right)$ was detected, which diluted the oxygen and inflammable gas. However, the pyrolysis products from WPU-6 were released earlier than those of WPU-0 because of the decomposition of $\mathrm{P}-\mathrm{O}-\mathrm{C}$ bonds in WPU at a low temperature, which could accelerate the formation of the char layer. ${ }^{40}$ From Fig. 7(b), we can infer that the evolved gases for WPU-6 release similar decomposition products to that of WPU-0. Moreover, the new absorption peaks at around $1268 \mathrm{~cm}^{-1}$ and $1002 \mathrm{~cm}^{-1}$ appear due to the structures of $\mathrm{P}=\mathrm{O}$ and $\mathrm{P}-\mathrm{O}-\mathrm{C}$ although the absorbance intensity is lower. It can be demonstrated that DOPO-DAM displays a gas phase mechanism. ${ }^{41}$

\section{Flame retardancy}

The LOI test is a kind of simple and fast method to evaluate the flammability of polymer materials. The influence of

Table 4 Pyrolysis products identified in the pyrochromatograms of WPU- 0 and WPU-6

\begin{tabular}{lcl}
\hline Retention $(\mathrm{min})$ & $m / z$ & Assigned structure \\
\hline 1.009 & 70 & $\mathrm{C}_{4} \mathrm{H}_{6} \mathrm{O}$ \\
1.134 & 112 & $\mathrm{C}_{5} \mathrm{H}_{4} \mathrm{O}_{3}$ \\
1.589 & 89 & $\mathrm{C}_{3} \mathrm{H}_{7} \mathrm{O}_{2} \mathrm{~N}$ \\
2.21 & 160 & $\mathrm{C}_{6} \mathrm{H}_{12} \mathrm{O}_{3} \mathrm{~N}_{2}$ \\
3.01 & 101 & $\mathrm{C}_{6} \mathrm{H}_{15}$ \\
8.90 & 90 & $\mathrm{C}_{4} \mathrm{H}_{10} \mathrm{O}_{2}$ \\
21.76 & 222 & \\
& 215 & \\
22.92 & &
\end{tabular}

Table 5 Cone calorimetric results and LOI values of FR-WPU

\begin{tabular}{lllll}
\hline Sample & WPU-0 & WPU-3 & WPU-6 & WPU-9 \\
\hline TTI (s) & 35 & 37 & 39 & 40 \\
$p$-HRR $\left(\mathrm{kW} \mathrm{m}^{-2}\right)$ & 976 & 949 & 797 & 577 \\
AvHRR $\left(\mathrm{kW} \mathrm{m}^{-2}\right)$ & 226 & 176 & 164 & 148 \\
THR $\left(\mathrm{MJ} \mathrm{m}^{-2}\right)$ & 64.48 & 50.1 & 47.55 & 42.45 \\
TSP $\left(\mathrm{m}^{2} \mathrm{~m}^{-2}\right)$ & 7.84 & 6.48 & 6.1 & 2.63 \\
Residues $(\mathrm{wt} \%)$ & 1.61 & 2.34 & 5.22 & 7.43 \\
LOI $(\%)$ & 18.4 & 23.2 & 27.4 & 31
\end{tabular}

phosphorus- and nitrogen-containing flame retardants on FRWPU films was investigated by LOI; the corresponding results are presented in Table 5. It was obviously seen that the LOI value of WPU-0 was only $18.4 \%$, which indicated that WPU films were flammable polymeric materials when exposed to fire. It can be seen that the addition of DOPO-DAM enhanced the LOI value, which increased to $31.0 \%$ at $9 \mathrm{wt} \%$. This was attributed to the thermal decomposition of DOPO groups, leading to the production of phosphoric acid and its analogues, which can act as dehydration and carbon-forming catalysts. Besides, according to the results of TGA and DTG, we can conclude that DOPODAM has high-temperature stability due to the cyclic structure of DOPO-DAM with a biphenyl group. ${ }^{42}$

To further determine the flame-retardant behavior in the early stage of the thermal decomposition process of FR-WPU films, pyrochromatograms were employed to analyze the pyrolysis products of WPU-0 and WPU-6. Fig. 8 shows the evolved pyrolysis products of WPU-0 and WPU-6 pyrolyzed at $280{ }^{\circ} \mathrm{C}$. It exhibited a wide variety of pyrolysis products of FRWPU to analyze the FR mechanism. The main pyrolysis products are shown in Fig. 8 and Table 4 . These products corresponded to the degradation of the polyurethane chain. ${ }^{43}$ Upon incorporating DOPO-DAM, the pyrolysis products of WPU-6 were similar to that of WPU-0. However, several new volatile products (retention times: 22.92 and $28.16 \mathrm{~min}$ ) appeared, as shown in Fig. 7(b). In addition, the decomposition process is illustrated in the mass spectrogram in Scheme 2. The main fragment was due to the $\mathrm{Ph}-\mathrm{PO}_{2}$ radical. After closer consideration of the mass spectrogram, $\mathrm{Ph}-\mathrm{PO}_{2}$ acted as a radical

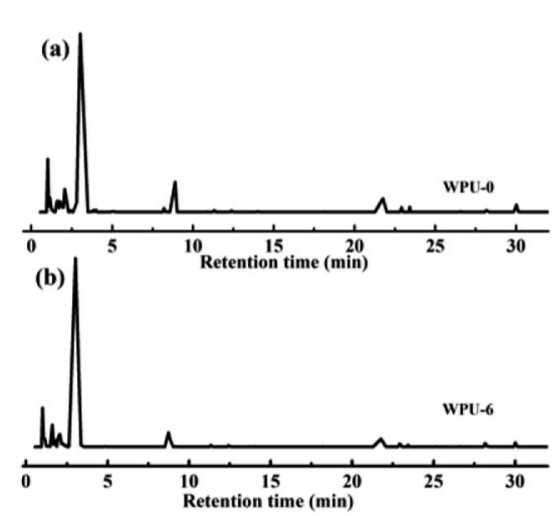

Fig. 8 Pyrochromatograms at $280^{\circ} \mathrm{C}$ of (a) WPU-0 and (b) WPU-6. 
scavenger and formed stable phenyl-containing products. The formation of these decomposition products was attributed to the splitting of $\mathrm{P}-\mathrm{C}$ and $\mathrm{P}-\mathrm{O}$ bonds of DOPO-based derivatives, which was regarded as important for the production of phosphorus-containing fragments in the gas phase.

To further evaluate the flame retardancy of FR-WPU in a real fire environment, a cone calorimeter test was conducted on FRWPU films. The results of the cone calorimeter tests of FR-WPU according to the time to ignition (TTI), heat release rate (HRR), total heat release (THR), smoke production rate (SPR) and total smoke production (TSP) to evaluate the combustion behaviour are discussed in this section. TTI, HRR, THR, SPR and TSP of various FR-WPU films are represented in Fig. 9 and summarized in Table 5 . It can be seen from Table 5 that the time to ignition (TTI) of WPU increases from $27 \mathrm{~s}$ for WPU-0 to $34 \mathrm{~s}$ for WPU-9 with the increase in the DOPO-DAM content. The delay in TTI is caused by the formation of carbon layers with the catalytic effect of the phosphorous groups before the burning of WPU. From Fig. 9(a and b) and Table 5, it can be observed that WPU0 is more suitable for the flame to spread after ignition with a single sharp peak with a peak heat release rate (pHRR) and THR value reaching $976 \mathrm{~kW} \mathrm{~m}^{-2}$ and $64.48 \mathrm{MJ} \mathrm{m}^{-2}$, respectively; the corresponding values for WPU-9 were only $577 \mathrm{~kW}$ $\mathrm{m}^{-2}$ and $42.45 \mathrm{MJ} \mathrm{m}^{-2}$. However, with the amount of DOPODAM increased the HRR curves after the first peak became more plateau tend to form a new peak with the extended burning time. The first peak was due to the formation of an intumescent carbon layer, which could reduce the transfer of matters. The second peak was due to the degradation of the protective layer which was continuously exposed to heat, leading to the formation of a new protective char layer in some formulations. ${ }^{\mathbf{4 4 , 4 5}}$ This indicated that there are differences in the fire behaviors between FR-WPU and WPU-0. For WPU-0, the incorporation of DOPO-DAM remarkably reduced the THR and pHRR values. The PHRR value of WPU-9 declined because of the quenching and charring effects of DOPO-DAM during combustion. The results showed that DOPO-DAM from FR-WPU delayed the propagation of the flame and obviously improved the flame retardancy of WPU.

Besides, SPR and TSP are important parameters in evaluating fire hazards of materials. The results of the smoke emission behaviors are shown in Fig. 9(c and d) and Table 5. The peak SPR value of FR-WPU decreased significantly with the increase in DOPO-DAM. WPU-9 showed the lowest TSP value $\left(2.63 \mathrm{~m}^{2} \mathrm{~m}^{-2}\right)$ than others. Compared with the result for WPU-0, the THR values of FR-WPU were $6.48,6.10$ and $2.63 \mathrm{~m}^{2} \mathrm{~m}^{-1}$, which reduced by $17.3 \%, 22.2 \%$, and $66.4 \%$, respectively. This can be because the incorporation of DOPO-DAM not only released quenching contents to prevent the free radical chain
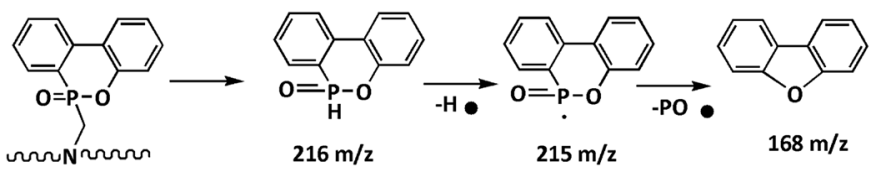

Scheme 2 The decomposition of FR-WPU in $\mathrm{N}_{2}$.
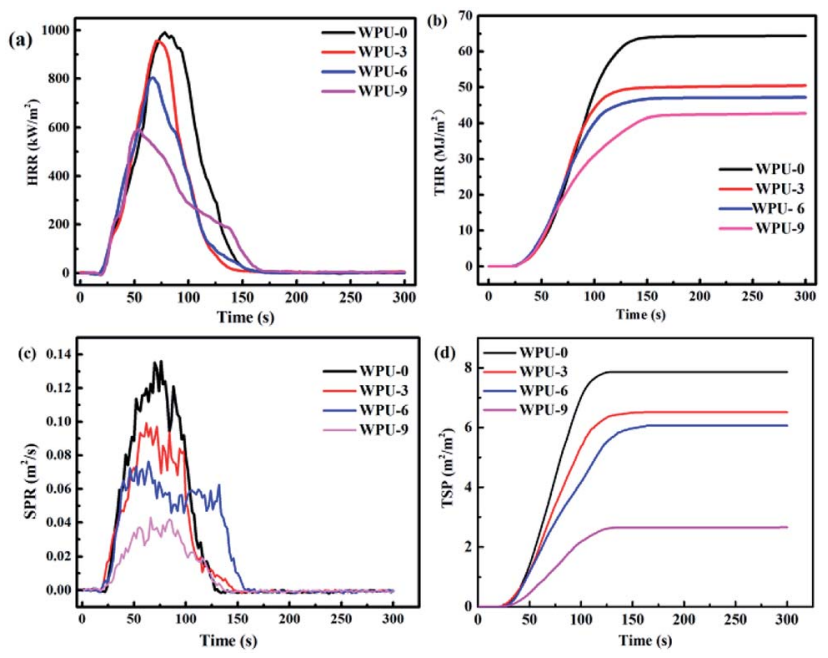

Fig. 9 HRR (a), THR (b), SPR (c) and TSP (d) curves of FR-WPU.

reaction, but also formed an intumescent carbon layer as a physical barrier, which prohibited the release of pyrolysis gases and smoke efficiently. Consequently, the abovementioned results illustrate that the conjugation of DOPO-DAM has a positive effect on inhibiting smoke emission.

The char residue of polymers obtained after combustion is an important parameter of flame retardants. The char residue increased from $1.61 \%$ to $7.43 \%$ (Table 5), which was in accordance with the TGA results. The digital photographs of the residues of FR-WPU after the cone calorimeter test are shown in Fig. 10. It can be clearly observed from Fig. 9(a) that WPU-0 is almost burnt out and only little residual char remains after burning. For WPU-9, a thick char layer is observed. When the DOPO-DAM content increased to $9 \%$, a more rigid and compact char residue for FR-WPU was obtained, which could act as a shield to prevent heat, air and pyrolysis product transfer. ${ }^{\mathbf{4 6}}$

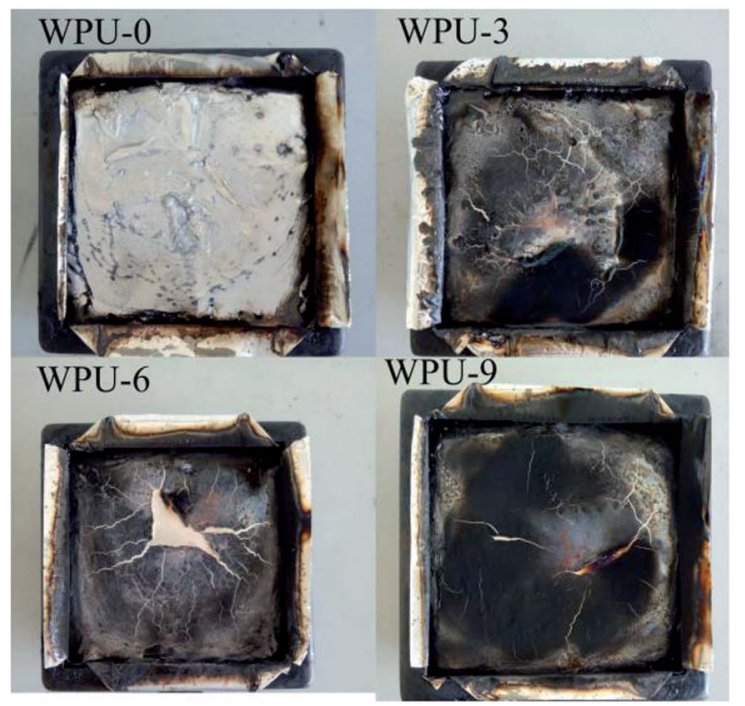

Fig. 10 Digital photographs of the residues of FR-WPU after the cone calorimeter test. 


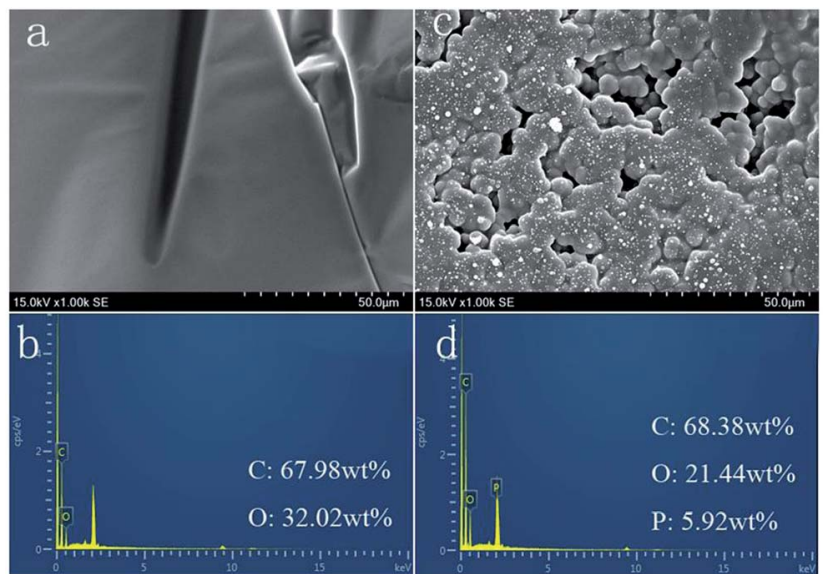

Fig. 11 SEM micrographs and EDS images of WPU-O ( $a$ and b) and WPU-6 (c and d).

Fig. 11 shows the SEM micrographs and EDS images of the surface from the WPU-0 and WPU- 6 residual chars after CCT. As shown in Fig. 11(a), the residual char of WPU-0 fragmented, resulting in a decline in the fire resistance. Compared with WPU-0, WPU-6 formed a coherent intumescent and thick char layer with holes on the surface of residual chars, demonstrating that the intumescent char structure could form a protective shield, preventing the transfer of heat, oxygen diffusion and release of flammable gases. The phosphoric acid analogues caused dehydration and formed a carbonization layer. The release of inert gases after the decomposition of DOPO-DAM resulted in the formation of an intumescent structure. As shown in Fig. 11, there are only carbon and oxygen elements in the residual char for WPU-0. However, for WPU-6, there are $5.92 \mathrm{wt} \%$ phosphorus elements besides carbon and oxygen. The results illustrated phosphorus enriched in residual chars after the chain extension of DOPO-DAM. This could be due to the formation of phosphorus-containing products, promoting dehydration and carbonization at a higher temperature. This also confirmed that DOPO-DAM was incorporated into WPU.

Based on the abovementioned results, it was not difficult to draw a conclusion that the reactive flame-retardant DOPO-DAM improved the flame retardancy of WPU. First, the cleavage of the urethane bonds in the hard segment of polyurethane resulted in the release of gases such as $\mathrm{CO}_{2}$ and $\mathrm{HCN}$ above $270{ }^{\circ} \mathrm{C}$. Meanwhile, the breakage of the $\mathrm{P}-\mathrm{C}$ bond in DOPO-DAM produced phosphoric acid, polyphosphoric acid and its derivatives. Then, the remaining polyol chains in the soft segment further decomposed. Simultaneously, the phosphoruscontaining compounds caused dehydration and formed a carbonization layer. Finally, the release of inert gas after the decomposition of DOPO-DAM led to the formation of an intumescent structure. The formed coherent intumescent and thick char layer with holes on the surface of residual chars could prevent the transfer of heat, oxygen diffusion and release of flammable gases. Another part of the inert gas could dilute the oxygen and inflammable gas. The possible flame-retardant mechanism of DOPO-DAM is illustrated in Scheme 3.
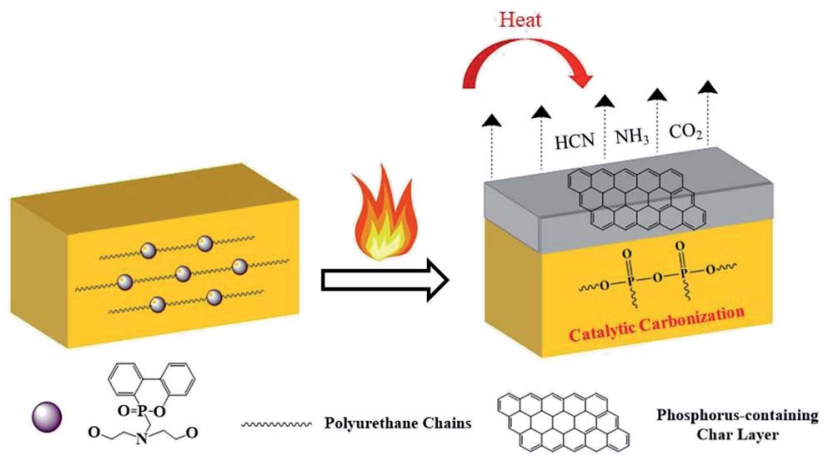

Scheme 3 Possible flame-retardant mechanism of DOPO-DAM.

\section{Conclusion}

In this work, an intumescent flame retardant (DOPO-DAM) containing phosphorus and nitrogen was synthesized through a two-step process and then incorporated into WPU to prepare a series of FRWPU materials. The chemical structures of DOPODAM were confirmed by ${ }^{1} \mathrm{H}$ NMR and ${ }^{31} \mathrm{P}$ NMR, and the synthesized FR-WPU films were characterized by FTIR. The incorporation of DOPO-DAM into WPU not only significantly increased the LOI value of FR-WPU, but also decreased HRR, THR, SPR and TSP. During combustion, DOPO-DAM decomposed and released nonflammable gases, which diluted oxygen and inflammable gases. Furthermore, it could act as a dehydrating agent, promoting the formation of a char layer to prevent the transfer of heat, oxygen diffusion and release of flammable gases. Thus, DOPO-DAM exhibited both gas-phase and condensed-phase flame-retardant effects on the WPU films.

\section{Conflicts of interest}

There are no conflicts to declare.

\section{Acknowledgements}

This work was funded by National Natural Science Foundation of China (No. 51773129, 51503130), Support Plan of Science and Technology Department of Sichuan Province, China (2017GZ0129, 2018SZ0174, 2019YFG0257), International Science and Technology Cooperation Program of Chengdu (2017-GH02-00068-HZ), Postdoctoral Research Foundation of Sichuan University (2018SCU12049) and Supported by Graduate Student's Research and Innovation Fund of Sichuan University (2018YJSY084).

\section{Notes and references}

1 X. Zhou, Y. Li, C. Q. Fang, S. J. Li, Y. L. Cheng, W. Q. Lei and X. J. Meng, J. Mater. Sci., 2015, 31, 7.

2 A. K. Nanda and D. A. Wicks, Polymer, 2006, 47, 6.

3 M. Keyvani, Adv. Polym. Technol., 2010, 22, 3.

4 M. S. Yen, P. Y. Tsai and P. D. Hong, Colloids Surf., A, 2006, 279, 1. 
5 M. S. Gaikwad, V. V. Gite, P. P. Mahulikar, D. G. Hundiwale and O. S. Yemul, Prog. Org. Coat., 2015, 86, 9.

6 C. Q. Wang, H. N. Lv, J. Sun and Z. S. Cai, Polym. Eng. Sci., 2013, 54, 11.

7 L. M. Gu and Y. Luo, Ind. Eng. Chem. Res., 2015, 54, 9.

8 D. K. Chattopadhyay and D. C. Webster, Prog. Polym. Sci., 2009, 34, 1068.

9 T. Ranganathan, J. Zilberman, R. J. Farris, E. B. Coughlin and T. Emrick, Macromolecules, 2006, 39, 18.

10 L. Zang, S. Wagner, M. Ciesielski, P. Müller and M. Döring, Polym. Adv. Technol., 2011, 22, 7.

11 P. Finocchiaro, G. A. Consiglio, A. Imbrogiano and S. Failla, Phosphorus, Sulfur Silicon Relat. Elem., 2007, 182, 8.

12 K. Wazarkar, M. Kathalewar and A. Sabnis, Prog. Org. Coat., $2015,87,75$.

13 M. Thirumal, K. Khastgir, G. B. Nando, Y. P. Naik and N. K. Singha, Polym. Degrad. Stab., 2010, 95, 6.

14 G. B. Huang, J. R. Cao, Y. J. Li, L. Han and X. Wang, Polym. Degrad. Stab., 2010, 95, 245.

15 Y. X. Jin, G. B. Huang, D. M. Han, P. G. Song, W. Y. Tang, J. S. Bao, R. R. Li and Y. L. Liu, Composites, Part A, 2016, 86, 9.

16 G. B. Huang, P. G. Song, L. N. Liu, D. M. Han, C. H. Ge, R. R. Li and Q. P. Guo, Carbon, 2016, 98, 689.

17 A. S. Dike, U. Tayfun and M. Dogan, Fire Mater., 2017, 41, 7. 18 T. Guler, U. Tayfun, E. Bayramli and M. Dogan, Thermochim. Acta, 2017, 647, 70.

19 W. C. Zhang, X. M. Li and R. Yang, Polym. Degrad. Stab., 2012, 97, 8.

20 B. Perret, B. Schartel, K. Stöß, M. Ciesielski, J. Diederichs, M. Döring, J. Krämer and V. Altstädt, Eur. Polym. J., 2011, 47, 5 .

21 J. Artner, M. Ciesielski, O. Walter, M. Döring, R. M. Perez, J. K. W. Sandler, V. Altstädt and B. Schartel, Macromol. Mater. Eng., 2008, 293, 503.

22 K. A. Salmeia and S. Gaan, Polym. Degrad. Stab., 2015, 113, 119.

23 C. S. Wu, Y. L. Liu and Y. S. J. Chiu, Appl. Polym. Sci., 2002, 85, 10 .

24 A. König and E. Kroke, Polym. Adv. Technol., 2011, 22, 1.

25 A. König and E. Kroke, Fire Mater., 2012, 36, 1.

26 S. Gaan, S. Y. Liang, H. Mispreuve, H. Perler, R. Naescher and M. Neisius, Polym. Degrad. Stab., 2015, 113, 180.
27 J. Y. Rao, M. P. Fernández-Ronco, M. Vong and S. Gaan, RSC Adv., 2017, 7, 69.

28 S. Yang, J. Wang, S. Q. Huo and L. Cheng, Ind. Eng. Chem. Res., 2015, 54, 32.

29 M. Kurańska, U. Cabulis, M. Auguścik, A. Prociak, J. Ryszkowska and M. Kirpluks, Polym. Degrad. Stab., 2016, 127, 11.

30 J. N. Gavgani, H. Adelnia, M. M. G. Git and F. Zafari, J. Mater. Sci., 2015, 131, 23.

31 Y. Bykov, S. Wagner, O. Walter, M. Döring, O. Fischer, D. Pospiech, T. Köppl and V. Altstädt, Heteroat. Chem., 2012, 23, 2.

32 S. Wang, Z. L. Du, X. Cheng, Y. S. Liu and H. B. Wang, J. Appl. Polym. Sci., 2018, 135, 16.

33 D. E. Fenton and G. Papageorgiou, Tetrahedron, 1996, 27, 31. 34 R. Yang, W. T. Hu, L. Xu, Y. Song and J. C. Li, Polym. Degrad. Stab., 2015, 122, 102.

35 L. A. Savas, T. K. Deniz, U. Tayfun and M. Dogan, Polym. Degrad. Stab., 2017, 135, 121.

36 M. Zhang, Z. Y. Luo, J. W. Zhang, S. G. Chen and Y. H. Zhou, Polym. Degrad. Stab., 2015, 120, 427.

37 S. M. Liu, J. B. Chen, J. Q. Zhao, Z. J. Jiang and Y. C. Yuan, Polym. Int., 2015, 64, 9.

38 H. Y. Ding, J. F. Wang, C. P. Wang and F. X. Chu, Polym. Degrad. Stab., 2016, 123, 43.

39 H. Y. Ding, C. l. Xia, J. F. Wang, C. P. Wang and F. X. Chu, J. Mater. Sci., 2016, 51, 10.

40 X. H. Li, Y. Z. Meng, Q. Zhu and S. C. Tjong, Polym. Degrad. Stab., 2003, 81, 1.

41 W. Z. Jiang, J. W. Hao and Z. D. Han, Polym. Degrad. Stab., 2012, 97, 4.

42 X. Liu, K. A. Salmeia, D. Rentsch, J. W. Hao and S. Gaan, J. Anal. Appl. Pyrolysis, 2017, 124, 219.

43 R. J. Jeng, S. M. Shau, J. J. Lin, W. C. Su and Y. S. Chiu, Eur. Polym. J., 2002, 38, 4.

44 X. L. Chen, C. Y. Ma and C. M. Jiao, Polym. Degrad. Stab., 2016, 129, 275.

45 X. F. Wu, L. H. Wang, C. Wu, J. H. Yu, L. Y. Xie, G. L. Wang and P. K. Jiang, Polym. Degrad. Stab., 2012, 97, 1.

46 M. J. Chen, Z. B. Shao, X. L. Wang, L. Chen and Y. Z. Wang, Ind. Eng. Chem. Res., 2012, 51, 29. 